\title{
European Cross-Sectional Survey of Current Care Practices for Duchenne Muscular Dystrophy Reveals Regional and Age-Dependent Differences
}

Julia Vry ${ }^{\mathrm{a}}$, Kathrin Gramsch ${ }^{\mathrm{a}}$, Sunil Rodger ${ }^{\mathrm{b}}$, Rachel Thompson ${ }^{\mathrm{b}}$, Birgit F. Steffensen ${ }^{\mathrm{c}}$, Jes Rahbek $^{\mathrm{c}}$, Sam Doerken ${ }^{\mathrm{d}}$, Adrian Tassoni ${ }^{\mathrm{a}}$, María de los Angeles Beytía ${ }^{\mathrm{a}}$, Velina Guergueltcheva ${ }^{\mathrm{e}}$, Teodora Chamova ${ }^{\mathrm{f}}$, Ivailo Tournev ${ }^{\mathrm{f}}$, Anna Kostera-Pruszczyk ${ }^{\mathrm{g}}$, Anna Kaminska $^{\mathrm{g}}$, Anna Lusakowska ${ }^{\mathrm{g}}$, Lenka Mrazovah ${ }^{\mathrm{h}}$, Lenka Pavlovskai ${ }^{\mathrm{i}}$ Jana Strenkovai, Petr Vondráček ${ }^{\mathrm{h}}$, Marta Garami ${ }^{\mathrm{j}}$, Veronika Karcagi ${ }^{\mathrm{j}}$, Ágnes Herczegfalvi ${ }^{\mathrm{k}}$, Katherine Bushby ${ }^{\mathrm{b}}$, Hanns Lochmüller ${ }^{\mathrm{b}}$ and Janbernd Kirschner ${ }^{\mathrm{a}, *}$

${ }^{a}$ Department of Neuropediatrics and Muscle Disorders, Medical Center-University of Freiburg, Freiburg, Germany

${ }^{\mathrm{b}}$ The John Walton Muscular Dystrophy Research Centre and MRC Centre for Neuromuscular Diseases, Institute of Genetic Medicine, Newcastle University, International Centre for Life, Central Parkway, Newcastle upon Tyne, UK

${ }^{\mathrm{c}}$ National Rehabilitation Center for Neuromuscular Diseases, Aarhus, Denmark

${ }^{\mathrm{d}}$ Institute for Medical Biometry and Statistics, Faculty of Medicine and Medical Center-University of Freiburg,

Freiburg, Germany

${ }^{\mathrm{e}}$ Medical University of Sofia, Department of Neurology, University Hospital Sofiamed and Bulgarian Neuromuscular Disorders Society, Sofia, Bulgaria

${ }^{\mathrm{f}}$ Medical University of Sofia, Department of Neurology, University Hospital Alexandrovska and Bulgarian Neuromuscular Disorders Society, Sofia, Bulgaria

${ }^{\mathrm{g}}$ Department of Neurology, Medical University of Warsaw, Warsaw, Poland

${ }^{\mathrm{h}}$ Department of Paediatric Neurology, University Hospital in Brno and Faculty of Medicine,

Masaryk University Brno, Czech Republic

${ }^{\mathrm{i}}$ Institute of Biostatistics and Analyses, Masaryk University Brno, Czech Republic

${ }^{\mathrm{j}}$ Department of Molecular Genetics and Diagnostics, National Institute of Environmental Health,

Budapest, Hungary

${ }^{\mathrm{k}}$ Department of Pediatrics, Semmelweis University, Budapest, Hungary

\footnotetext{
${ }^{*}$ Correspondence to: Prof. Dr. Janbernd Kirschner, Department of Neuropediatrics and Muscle Disorders, Medical Center - University of Freiburg, Mathildenstraße 1, 79116 Freiburg, Germany. Tel.: +49761 270 44970; Fax: +49 761270 44460; E-mail: janbernd.kirschner@uniklinik-freiburg.de.
} 


\begin{abstract}
.
Background: Publication of comprehensive clinical care guidelines for Duchenne muscular dystrophy (DMD) in 2010 was a milestone for DMD patient management. Our CARE-NMD survey investigates the neuromuscular, medical, and psychosocial care of DMD patients in Europe, and compares it to the guidelines.

Methods: A cross-sectional survey of 1677 patients contacted via the TREAT-NMD patient registries was conducted using self-report questionnaires in seven European countries.

Results: Survey respondents were 861 children and 201 adults. Data describe a European DMD population with mean age of 13.0 years (range $0.8-46.2$ ) of whom $53 \%$ had lost ambulation (at 10.3 years of age, median). Corticosteroid medication raised the median age for ambulatory loss from 10.1 years in patients never medicated to 11.4 years in patients who received steroids $(p<0.0001)$. The majority of patients reported receiving care in line with guidelines, although we identified significant differences between countries and important shortcomings in prevention and treatment. Summarised, $35 \%$ of patients aged $\geq$ nine years received no corticosteroid medication, $24 \%$ of all patients received no regular physiotherapy, echocardiograms were not performed regularly in $22 \%$ of patients, pulmonary function was not regularly assessed in $71 \%$ of non-ambulatory patients. Patients with regular follow-up by neuromuscular specialists were more likely to receive care according to guidelines, were better satisfied, and experienced shorter unplanned hospitalization periods.
\end{abstract}

Keywords: Duchenne muscular dystrophy, standards of care, corticosteroid treatment, functional status

\section{INTRODUCTION}

Duchenne muscular dystrophy (DMD) is a severe form of muscular dystrophy, affecting one in 3,800-6,300 live male births [1]. The natural disease course is characterised by progressive muscle weakness leading to ambulatory loss by 7-12 years of age [2]. Respiratory insufficiency and cardiomyopathy develop in the second decade, and can cause early death. Even though DMD remains incurable, proactive symptomatic, multidisciplinary treatment can raise life expectancy into the fourth decade. Similar to other rare diseases, a treating physician with disease-specific clinical knowledge and experience is imperative for best-practice treatment. The publication of standardised care guidelines [3, 4] in 2010 was an important step towards improving DMD patient care. These guidelines were reproduced as "family guides", that are now translated into 37 languages, and distributed to patients and health care providers via patient organisations, the TREAT-NMD network, and patient registries. We set out to survey the extent to which these guidelines have been incorporated into clinical practice across European countries in both Eastern and Western regions. Healthcare research in rare diseases is challenging, with patient registries often the only resource identifying patients with a given disease. The objective of the EU-financed CARE-NMD project (www.carenmd.eu) was to evaluate current care and quality of life in DMD patients in Europe. Here we present information describing current care of $>1,000$ children and adults with DMD in seven European countries.

\section{METHODS}

\section{Patients}

We conducted a cross-sectional, international survey on care practices and quality of life in DMD patients in Bulgaria, the Czech Republic, Denmark, Germany, Hungary, Poland, and the United Kingdom. Countries were selected because of well-established DMD patient registries and to broadly represent different healthcare systems and public expenditure on health. The health expenditure to gross domestic product ratio is below the EU average in all Eastern European and above the average in all Western European countries participating in this project. Therefore we compared key outcome measures between the two groups of countries. Children and adults with DMD were recruited through direct contact from TREATNMD national DMD patient registries. Patient registration in these national registries is voluntary. In Germany and the United Kingdom registration is initiated by the patients/families themselves while the other countries use a clinic-based approach for registration. All registries store patient age with clinical and genetic details [5]. Prior to our survey, each local CARE-NMD project team contacted national patient organisations to encourage registration. Every patient registered as having DMD was invited to participate in the survey. The data 
presented here is only based on self-report of patients and their families. This study was approved by the ethics committee in Freiburg, Germany, and the TREAT-NMD Global Database Oversight Committee (http://www.treat-nmd.eu/about/governance/ tgdoc/).

\section{Data collection and evaluation}

Questionnaire development and methods of distribution are described in the supplemental material. Data were collected between September 2011 and April 2012, imported into a single SPSS (Version 22) database, then analysed using SPSS and Excel. The Kolmogorov-Smirnov test was used to test for a normal data distribution. Group parameters were compared using the Wilcoxon test when data were not normally distributed, and the Student's $t$-test or ANOVA when normally distributed. Cox regression analysis was used to analyse factors influencing age at loss of ambulation.

\section{RESULTS}

\section{Surveyed patient cohort represents a European cross-section}

Of the 1180 returned questionnaires, 118 were excluded from data analysis because the questionnaire was submitted empty, answered twice (online) by the same patient, or the clinical data or registry categorised the patient as Becker muscular dystrophy. Cleansing yielded 1062 datasets (final response rate $63.3 \%$ ) for analysis. Patient distribution was skewed towards Western European countries with the exception of Poland. Patients ranged from 0.8 to 46.2 years of age in the surveyed cohort. Mean patient age was considerably higher in Danish patients, reflecting more adult survey participants (Table 1).

\section{Current DMD Diagnosis in Europe}

DMD can either be diagnosed by the absence of dystrophin in a muscle biopsy or by genetic testing for $D M D$ mutations. Guidelines recommend genetic testing for all patients, and $71.6 \%$ of DMD patients reported additionally or exclusively receiving $D M D$ mutation screening (Table 1). Our survey identified 302 patients, including 91 (30.1\%) adults, who self-reported never having received a genetic diagnostic confirmation, and detected country-specific differences, with more frequent genetic testing in Eastern than Western European countries (Table 1). Of the 107 patients diagnosed $\leq 24$ months prior to the survey, $93.5 \%$ reported genetic testing. Across all countries, $80.5 \%$ of patients had been informed about the possibility of genetic counselling, but only $65 \%$ felt that information provided was sufficient. Separating responders who reported their age into three age groups revealed that younger patient generations were diagnosed significantly earlier (Table 2).

\section{Neuromuscular centre care shortened unplanned hospital stay and provided care according to standards guidelines}

Regular (at least 1-2 times yearly) check-ups at a neuromuscular centre are recommended. We hypothesised patients were more likely to receive care according to consensus guidelines at neuromuscular centres, and formed two subgroups for process indicator evaluation. Most respondents visited a neuromuscular centre at least once yearly for a check-up (Table 3), which we defined as "regular visitors". "Irregular visitors" included patients visiting centres less frequently or never. Patients never seeking centre care claimed [1] centres were too far away $(n=49)$, [2] they were not aware centres existed $(n=19)$, or [3] they did not need a neuromuscular specialist $(n=8)$. Regular visitors were significantly younger than irregular visitors, received more frequent cardiac and pulmonary check-ups, were more likely to receive corticosteroid treatment, were better informed about all surveyed aspects of DMD (Fig. 2), and were more satisfied with overall treatment. The degree of satisfaction was similar across all age groups, but differed largely between countries, with the highest satisfaction reported for Denmark (Fig. 3). We expected hospital admissions would be fewer in patients attending neuromuscular centres, and compared regular and irregular visitors. Surprisingly, the proportion of unplanned admissions did not differ between groups, but the mean duration of stay was significantly longer in irregular visitors (Table 5).

\section{Corticosteroid treatment in Europe prolongs ambulatory phase in DMD patients}

The outcome indicator "walking ability" was analysed and the influence of corticosteroid treatment assessed. Ambulation was lost in $53.4 \%$ of responders 
at similar ages across all countries (Table 3 ). Steroid treatment should be initiated when the child reaches the plateau-phase, occurring around four to eight years of age [3], inferring that DMD patients with typical disease course who have reached nine years of age should be taking or have tried corticosteroids. However, $34.8 \%$ of these 704 patients had never taken corticosteroids, $52.8 \%$ because doctors had not suggested and $44.2 \%$ because parents objected to the treatment (Table 3). Steroid use differed substantially across the surveyed countries, while starting age was similar (Table 3). Most frequent reasons for discontinuing corticosteroid treatment were ambulatory loss $(n=98)$ or intolerable side effects $(n=88)$. Notably, only $21 \%$ of nonambulatory patients reported current corticosteroid medication. We compared age at ambulatory loss in steroid naïve patients and patients who received corticosteroid treatment, regardless of age of initiation, duration of treatment, or dose. Ambulation was lost significantly later in corticosteroid-treated patients (Fig. 1). This effect was independent of country, care at a neuromuscular centre, or receipt of physiotherapy, none of which significantly influenced age at ambulatory loss.

\section{Rehabilitative, cardiac and pulmonary management is frequently below recommended standards in Europe}

Care standards recommend preventive measures to minimize contractures starting in the presymptomatic stage. The majority of our cohort reported receiving stretching or physical exercises from a qualified professional $(7.4 \%=$ never $)$, but extraordinary differences existed between countries with the highest provision in Germany $(>90 \%)$ and the lowest in the UK $(<50 \%)$ (Table 3 ). Adults were generally less likely than children to receive physiotherapy (Table 2). It is unlikely that the 242 patients who reported not currently receiving physiotherapy were performing stretching exercises at home, since patient/parent information levels about exercise were inadequate in approximately half these responders.

Echocardiogram frequency was chosen as a process indicator for cardiac care. Annual echocardiography is recommended in patients $\geq 10$ years of age to detect left ventricular dysfunction for early cardioprotective treatment. Our survey revealed that almost one quarter of patients, especially adults, did not receive regular echocardiograms (Tables 2 and 4).

Table 1

Age and diagnostic history of our European DMD patient cohort broken down by country

\begin{tabular}{|c|c|c|c|c|c|c|c|c|}
\hline \multirow[t]{2}{*}{ Characteristic $^{\mathrm{a}}$} & \multirow[t]{2}{*}{$\begin{array}{l}\text { Total cohort } \\
(n=1062)\end{array}$} & \multicolumn{4}{|c|}{$\begin{array}{l}\text { Eastern Europe } \\
\quad(n=328)\end{array}$} & \multicolumn{3}{|c|}{$\begin{array}{l}\text { Western Europe } \\
\qquad(n=734)\end{array}$} \\
\hline & & $\mathrm{BG}$ & $\mathrm{CZ}$ & $\mathrm{HU}$ & PL & DK & GE & UK \\
\hline $\begin{array}{l}\text { Number of patient } \\
\text { questionnaires sent out }\end{array}$ & 1677 & 73 & 191 & 70 & 246 & 131 & 545 & 421 \\
\hline Response rate $(\%)$ & $63 \%$ & $55 \%$ & $47 \%$ & $81 \%$ & $58 \%$ & $67 \%$ & $77 \%$ & $54 \%$ \\
\hline $\begin{array}{l}\text { Number of patient } \\
\text { questionnaires evaluated }\end{array}$ & 1062 & 40 & 89 & 57 & 142 & 88 & 420 & 226 \\
\hline (\% total evaluated) & $(100 \%)$ & $(3.8 \%)$ & $(8.4 \%)$ & $(5.4 \%)$ & $(13.4 \%)$ & $(8.3 \%)$ & $(39.5 \%)$ & $(21.3 \%)$ \\
\hline $\begin{array}{l}\text { Number of adult patients }{ }^{\mathrm{b}} \\
\text { (proportion) }\end{array}$ & $\begin{array}{c}201 / 1062 \\
(18.9 \%)\end{array}$ & $\begin{array}{c}8 / 40 \\
(20 \%)\end{array}$ & $\begin{array}{c}11 / 89 \\
(12.4 \%)\end{array}$ & $\begin{array}{c}5 / 57 \\
(8.8 \%)\end{array}$ & $\begin{array}{l}16 / 142 \\
(11.3 \%)\end{array}$ & $\begin{array}{c}43 / 88 \\
(48.9 \%)\end{array}$ & $\begin{array}{l}77 / 420 \\
(18.3 \%)\end{array}$ & $\begin{array}{l}41 / 226 \\
(18.1 \%)\end{array}$ \\
\hline $\begin{array}{l}\text { Mean patient age in } \\
\text { years } \pm \text { SD at questionnaire } \\
\text { completion }(n=1062)\end{array}$ & $13.0 \pm 7.2$ & $13.7 \pm 6.6$ & $11.1 \pm 5.3$ & $10.5 \pm 5.5$ & $12.1 \pm 6.1$ & $20.3 \pm 10.5$ & $12.3 \pm 6.9$ & $12.9 \pm 6.7$ \\
\hline $\begin{array}{l}\text { Mean patient age at diagnosis } \\
\text { in years } \pm \text { SD } \\
(n=971 / 1062)\end{array}$ & $4.3 \pm 2.5$ & $6.4 \pm 4.0$ & $3.7 \pm 0.8$ & $4.6 \pm 2.7$ & $5.3 \pm 1.4$ & $4.6 \pm 1.3$ & $3.8 \pm 2.4$ & $4.1 \pm 2.0$ \\
\hline $\begin{array}{l}\text { Mean time from report of first } \\
\text { symptoms to diagnosis in } \\
\text { years } \pm \text { SD }(n=833 / 1062)\end{array}$ & $1.3 \pm 1.8$ & $2.0 \pm 3.5$ & $0.8 \pm 1.2$ & $1.9 \pm 2.3$ & $1.4 \pm 2.0$ & $1.3 \pm 1.5$ & $1.4 \pm 1.8$ & $1.1 \pm 1.3$ \\
\hline $\begin{array}{l}\text { Patients reporting having } \\
\text { genetic testing for DMD } \\
\text { mutations }(n=1062)\end{array}$ & $71.6 \%$ & $90.0 \%$ & $87.6 \%$ & $96.5 \%$ & $79.6 \%$ & $53.4 \%$ & $79.8 \%$ & $42.5 \%$ \\
\hline $\begin{array}{l}\text { Patients reporting diagnosis } \\
\text { by muscle biopsy } \\
(n=1062)\end{array}$ & $49.3 \%$ & $20.0 \%$ & $53.9 \%$ & $42.1 \%$ & $57.0 \%$ & $58.0 \%$ & $48.3 \%$ & $48.2 \%$ \\
\hline
\end{tabular}

$\mathrm{SD}=$ standard deviation, $\mathrm{BG}=$ Bulgaria, $\mathrm{CZ}=$ Czech Republic, $\mathrm{GE}=$ Germany, $\mathrm{DK}=$ Denmark, $\mathrm{HU}=$ Hungary, $\mathrm{PL}=\mathrm{Poland}, \mathrm{UK}=\mathrm{United}$ Kingdom. ${ }^{a}$ Numbers in row titles indicate the total number of evaluable responses in our cohort of 1062 patients. ${ }^{b}$ Defined as $\geq 18$ years of age. 


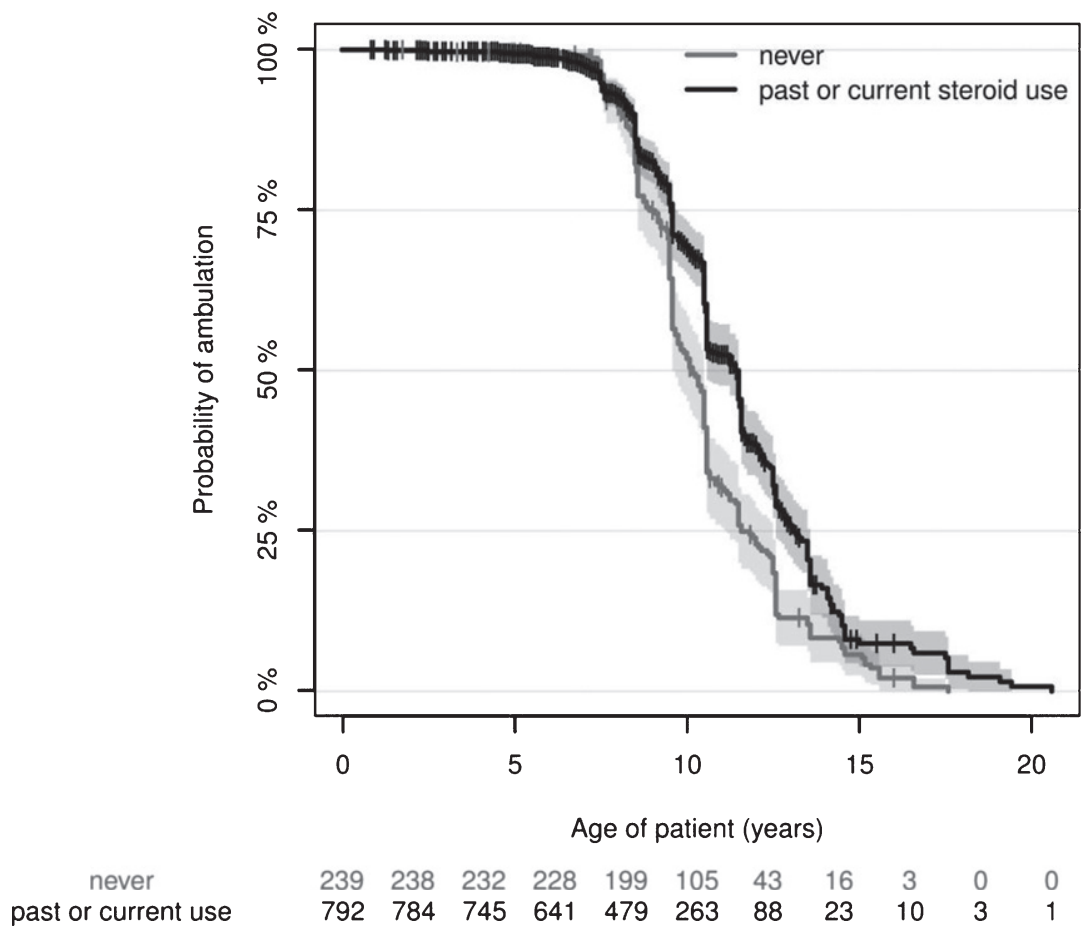

Fig. 1. The Kaplan-Meier estimates and their confidence intervals (shaded areas) show a clear distinction that patients with current steroid use show significantly loss of ambulation. The Kaplan-Meier estimate of the median time of loss of ambulation (x-axis) is 10.08 (9.58-10.50 95\% Confidence Interval) years versus 11.42 (10.45-11.50 95\% CI) years in the "never" versus "past or current steroid use" groups. The tick marks indicate right-censored data, i.e. patients who were still ambulatory at the time of recording. The 'numbers at risk' are shown below the plot and correspond to the $\mathrm{x}$-axis, indicating how many patients were available for estimation. Cox regression analysis, $p<0.0001$ in the corticosteroid-user group, with 1.34 years difference between group medians.

Table 2

Results of selected outcome and care indicators of DMD patient care for the whole cohort and different age groups in the cohort

\begin{tabular}{|c|c|c|c|c|}
\hline \multirow[t]{2}{*}{ Characteristic } & \multirow[t]{2}{*}{ Whole cohort } & \multicolumn{2}{|c|}{ Children } & \multirow[t]{2}{*}{ adults $^{\mathrm{c}}$} \\
\hline & & Young $^{\mathrm{a}}$ & Intermediate $^{\mathrm{b}}$ & \\
\hline Mean patient age in years \pm SD at diagnosis ${ }^{\mathrm{d}}$ & $\begin{array}{c}4.3 \pm 2.5 \\
(n=971 / 1062)^{\mathrm{e}}\end{array}$ & $\begin{array}{c}2.3 \pm 1.3 \\
(n=122 / 137)\end{array}$ & $\begin{array}{c}4.4 \pm 2.3 \\
(n=665 / 724)\end{array}$ & $\begin{array}{c}5.2 \pm 2.9 \\
(n=184 / 201)\end{array}$ \\
\hline $\begin{array}{l}\text { Mean time from report of first symptoms } \\
\text { to diagnosis in years }{ }^{f}\end{array}$ & $\begin{array}{c}1.3 \pm 1.8 \\
(n=833 / 1062)\end{array}$ & $\begin{array}{c}0.7 \pm 0.8 \\
(n=95 / 137)\end{array}$ & $\begin{array}{c}1.4 \pm 1.7 \\
(n=573 / 724)\end{array}$ & $\begin{array}{c}1.6 \pm 2.3 \\
(n=165 / 201)\end{array}$ \\
\hline Patients receiving physiotherapy & $\begin{array}{c}72.8 \% \\
(n=1015 / 1062)\end{array}$ & $\begin{array}{c}78.1 \% \\
(n=819 / 861)\end{array}$ & & $\begin{array}{c}67.9 \% \\
(n=196 / 201)\end{array}$ \\
\hline $\begin{array}{l}\text { Patients ( } \geq 10 \text { years of age) receiving } \\
\text { echocardiography according to guidelines }\end{array}$ & $\begin{array}{c}77.9 \% \\
(n=635 / 660)\end{array}$ & $\begin{array}{c}82.2 \% \\
(n=439 / 459)\end{array}$ & & $\begin{array}{c}67.4 \% \\
(n=196 / 201)\end{array}$ \\
\hline $\begin{array}{l}\text { Patients who reported unplanned hospital } \\
\text { admissions within past } 2 \text { years }\end{array}$ & $\begin{array}{c}13.6 \% \\
(n=1062)\end{array}$ & $\begin{array}{c}8.9 \% \\
(n=861)\end{array}$ & & $\begin{array}{c}25.4 \% \\
(n=201)\end{array}$ \\
\hline
\end{tabular}

${ }^{\mathrm{a}}<6$ years of age at questionnaire response $(n=137 / 1062) .{ }^{\mathrm{b}} 6-17$ years of age at questionnaire response $(n=724 / 1062) .{ }^{c} \geq 18$ years of age at questionnaire response $(n=201 / 1062)$. ${ }^{\mathrm{d}}$ Anova between all age groups $=p<0.0001$. ${ }^{\mathrm{e}}$ Numbers in parenthesis indicate the total number of evaluable responses per the total number of patients in our cohort who correspond to the descriptor. ${ }^{\mathrm{f}}$ Anova between all age groups $=p<0.01$. Both muscle biopsy and genetic testing diagnoses were considered. ${ }^{g}$ Recommended once yearly.

Echocardiogram frequency differed markedly between countries, with lower frequencies in some Eastern European countries and Denmark (Table 3). A small proportion $(n=174)$ could report their left ventricular ejection fraction (LVEF) of whom 72 patients reported an $\mathrm{LVEF}<55 \%$, signifying cardiomyopathy [7]. Of these, only $69.4 \%$ received treat- ment for cardiomyopathy with either beta-blockers or angiotensin-converting enzyme inhibitors. Of the 102 patients reporting an $\mathrm{LVEF} \geq 55 \%, 27.5 \%$ were receiving prophylactic medication.

Care guidelines recommend pulmonary function assessment yearly in ambulatory and twice yearly in non-ambulatory patients ( $\geq 6$ years). Adherence 
Table 3

Selected outcome and process indicators for patient care in our European DMD patient cohort broken down by country

\begin{tabular}{|c|c|c|c|c|c|c|c|c|}
\hline \multirow[t]{2}{*}{ Characteristic $^{\mathrm{a}}$} & \multirow[t]{2}{*}{ Total cohort } & \multicolumn{4}{|c|}{$\begin{array}{l}\text { Eastern Europe } \\
(n=328 / 1062)\end{array}$} & \multicolumn{3}{|c|}{$\begin{array}{l}\text { Western Europe } \\
(n=734 / 1062)\end{array}$} \\
\hline & & $\mathrm{BG}$ & $\mathrm{CZ}$ & $\mathrm{HU}$ & PL & DK & GE & UK \\
\hline $\begin{array}{l}\text { Patients reporting loss of ambulation } \\
\qquad(n=567 / 1049)\end{array}$ & $53.4 \%$ & $62.5 \%$ & $49.4 \%$ & $50.0 \%$ & $50.7 \%$ & $75.0 \%$ & $52.4 \%$ & $50.5 \%$ \\
\hline $\begin{array}{l}\text { Mean patient age at loss of } \\
\text { ambulation in years } \pm \text { SD } \\
(n=549 / 567)\end{array}$ & $10.4^{\mathrm{b}} \pm 2.4$ & $10.2 \pm 2.0$ & $9.9 \pm 1.8$ & $9.8 \pm 3.1$ & $9.9 \pm 1.8$ & $9.9 \pm 2.4$ & $10.9 \pm 2.7$ & $10.3 \pm 2.1$ \\
\hline $\begin{array}{l}\text { Non-ambulatory patients reporting } \\
\text { being able to sit unsupported } \\
(n=548 / 567)\end{array}$ & $51.8 \%$ & $66.7 \%$ & $75.0 \%$ & $85.2 \%$ & $49.2 \%$ & $11.1 \%$ & $51.6 \%$ & $56.5 \%$ \\
\hline $\begin{array}{l}\text { Non-ambulatory patients requiring } \\
\text { a spinal brace to } \text { sit }^{\mathrm{c}}(n=548 / 567)\end{array}$ & $44.0 \%$ & $29.2 \%$ & $22.7 \%$ & $14.8 \%$ & $46.0 \%$ & $79.4 \%$ & $46.6 \%$ & $36.1 \%$ \\
\hline $\begin{array}{l}\text { Non-ambulatory patients incapable } \\
\text { of sitting }(n=548 / 567)\end{array}$ & $4.2 \%$ & $0 \%$ & $2.3 \%$ & $0 \%$ & $4.8 \%$ & $9.5 \%$ & $1.8 \%$ & $7.4 \%$ \\
\hline $\begin{array}{l}\text { Non-ambulatory patients reporting } \\
\text { current steroid use }(552 / 567)\end{array}$ & $21.0 \%$ & $8.0 \%$ & $7.5 \%$ & $18.5 \%$ & $22.2 \%$ & $6.2 \%$ & $21.6 \%$ & $35.7 \%$ \\
\hline $\begin{array}{l}\text { Mean age in years } \pm \text { SD of steroid } \\
\text { treatment start }(n=478 / 637)\end{array}$ & $6.1 \pm 2.4$ & $6.4 \pm 1.9$ & $6.9 \pm 2.3$ & $6.5 \pm 2.2$ & $5.9 \pm 2.6$ & $5.8 \pm 2.0$ & $5.8 \pm 2.5$ & $6.4 \pm 2.4$ \\
\hline $\begin{array}{l}\text { Patients } \geq 9 \text { years of age } \\
(n=704 / 730) \text { reporting current } \\
\text { or past steroid use }\end{array}$ & $65.2 \%$ & $29.0 \%$ & $32.0 \%$ & $53.1 \%$ & $71.4 \%$ & $34.2 \%$ & $72.8 \%$ & $83.6 \%$ \\
\hline $\begin{array}{l}\text { Mean age in years } \pm \text { SD of steroid } \\
\text { treatment start in patients aged } \\
\geq 9 \text { years }(n=335 / 730)\end{array}$ & $6.6 \pm 2.6$ & $7.2 \pm 1.9$ & $7.4 \pm 2.6$ & $7.8 \pm 1.1$ & $6.5 \pm 2.9$ & $6.1 \pm 2.0$ & $6.1 \pm 2.7$ & $6.9 \pm 2.5$ \\
\hline $\begin{array}{l}\text { Patients regularly }{ }^{\mathrm{d}} \text { visiting } \\
\text { a neuromuscular centre } \\
(n=1027 / 1062)\end{array}$ & $81.9 \%$ & $43.6 \%$ & $82.1 \%$ & $82.5 \%$ & $56.9 \%$ & $81.6 \%$ & $88.5 \%$ & $92.1 \%$ \\
\hline $\begin{array}{l}\text { Patients receiving physiotherapy } \\
\qquad(n=1015 / 1062)\end{array}$ & $76.2 \%$ & $53.8 \%$ & $51.9 \%$ & $76.8 \%$ & $84.1 \%$ & $90.7 \%$ & $92.0 \%$ & $48.4 \%$ \\
\hline $\begin{array}{l}\text { Sufficient instructions to perform } \\
\text { exercises in patients without } \\
\text { current physiotherapy } \\
(n=238 / 240)\end{array}$ & $53.3 \%$ & $16.7 \%$ & $56.4 \%$ & $25.0 \%$ & $50.0 \%$ & $62.5 \%$ & $21.9 \%$ & $70.6 \%$ \\
\hline $\begin{array}{l}\text { Patients }(\geq 10 \text { years of age) receiving } \\
\text { echocardiography } \geq \text { once yearly } \\
(n=633 / 660)\end{array}$ & $77.9 \%$ & $64.0 \%$ & $65.9 \%$ & $85.2 \%$ & $54.2 \%$ & $63.0 \%$ & $90.7 \%$ & $81.0 \%$ \\
\hline $\begin{array}{l}\text { Ambulatory patients ( } \geq 6 \text { years } \\
\text { of age), receiving lung function } \\
\text { testing }{ }^{\mathrm{e}} \text { according to international } \\
\text { care recommendations }{ }^{\mathrm{f}} \\
(n=336 / 348)\end{array}$ & $62.8 \%$ & $76.9 \%$ & $44.8 \%$ & $71.4 \%$ & $32.0 \%$ & $61.1 \%$ & $74.2 \%$ & $66.3 \%$ \\
\hline $\begin{array}{l}\text { Non-ambulatory patients ( } \geq 6 \text { years } \\
\text { of age), receiving lung function } \\
\text { testing according to international } \\
\text { care recommendations }{ }^{\mathrm{e}} \\
(n=547 / 567)\end{array}$ & $30.5 \%$ & $4.3 \%$ & $5.0 \%$ & $14.8 \%$ & $5.8 \%$ & $18.5 \%$ & $44.1 \%$ & $45.5 \%$ \\
\hline $\begin{array}{l}\text { Non-ambulatory patients reporting } \\
\text { spinal inspection }(n=540 / 567)^{\mathrm{g}}\end{array}$ & $20.2 \%$ & $4.3 \%$ & $7.3 \%$ & $11.1 \%$ & $2.8 \%$ & $7.9 \%$ & $32.2 \%$ & $26.0 \%$ \\
\hline
\end{tabular}

$\mathrm{SD}=$ standard deviation, $\mathrm{BG}=$ Bulgaria, $\mathrm{CZ}=$ Czech Republic, $\mathrm{GE}=$ Germany, $\mathrm{DK}=$ Denmark, $\mathrm{HU}=$ Hungary, $\mathrm{PL}=\mathrm{Poland}, \mathrm{UK}=\mathrm{United}$ Kingdom. ${ }^{a} n$ number in row and column titles indicate the total number of evaluable responses per the total number of patients in our cohort who correspond to the descriptor. ${ }^{b}$ Range of age at loss of ambulation was $1.33-20.58$ years and median 10.3 years. ${ }^{\mathrm{c}}$ Mean age $=22.0 \pm 8.3$ years. ${ }^{\mathrm{d}}$ Regularly defined as at least 1-2 times per year. ${ }^{\mathrm{e}}$ Lung function measured by forced vital capacity (FVC). ${ }^{\mathrm{f}}$ International care recommendation recommends measuring FVC annually in ambulatory patients and bi-annually in non-ambulatory patients. ${ }^{\mathrm{g}} \mathrm{Minimal}$ recommendations are visual inspection every 6 months.

to guidelines was low in ambulatory and strikingly bad in non-ambulatory patients (Table 4), and pronounced differences between Eastern and Western European countries were revealed (Table 3). Many patients reported being insufficiently informed about DMD-related breathing problems (Fig. 2). Our survey identified lung function awareness as a problem area in DMD care, with only $31.3 \%$ of ambulatory 
and $39.9 \%$ of non-ambulatory patients knowing their current ( $<12$ months) FVC. We surveyed need or use of breathing assistance in all 1062 patients, and 154 patients (mean age $26.6 \pm 6.5$ years) reported using mechanical ventilation. Of patients not using mechanical ventilation, $20.6 \%$ (7/34) reported an $\mathrm{FVC}<20 \%$. This subgroup is very likely to benefit from ventilatory support [7].

\section{DISCUSSION}

Here we present results from the largest crosssectional survey conducted on DMD patients in Europe. Results comprehensively describe patient health status and current care practice in Eastern and Western European countries. Our analyses identify areas where care does not reach internationally defined recommendations and highlights trends in patient care. Our patient-centred approach goes beyond registry information and provides an insight into real-world experiences of DMD care. Patient registries represent a unique source for obtaining data from large cohorts of patients with a confirmed diagnosis of DMD, since hospital coding uses a single ICD code for all muscular dystrophy types. Since registry participants are likely to be more actively engaged in their medical care and receive better care than unregistered patients, we attempted to increase registered patient numbers in collaboration with patient advocacy groups prior to survey to reduce this possible bias. The exact prevalence of DMD is not known for the different European countries and probably varies significantly according to differences in mortality. For most countries studied in this project it can be estimated that less than half of the total DMD population are captured in patient registries. Therefore non-registered patients and non-responders add additional bias to our results. Due to the anonymity of the survey it was not possible to further analyse this bias by comparing characteristics of responders and non-responders. In addition, it might be possible that some respondents were familiar with the care recommendations and answered questions accordingly even if examinations did not really happen (desirability bias). In addition, self-reporting may introduce error from incorrect comprehension of questions or inaccurate memory of treatment/care. This may explain the extremely low number of UK patients reporting genetic testing, while the national registry reports all registered patients had genetic confirmation of DMD.

\section{Percentage of patients reporting they received sufficient information}

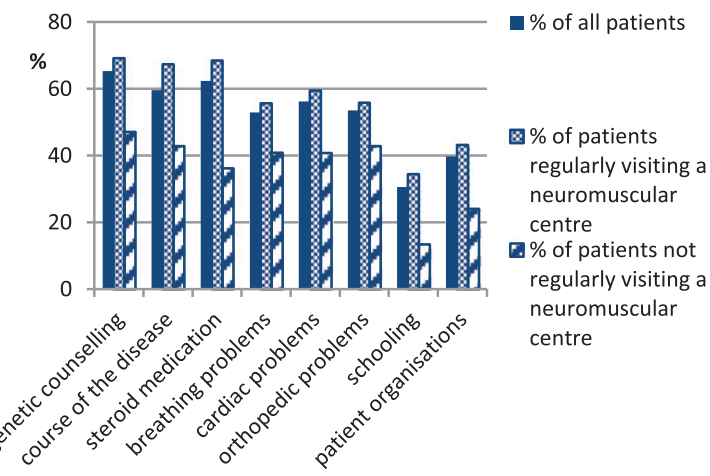

Fig. 2. Percentage of patients that felt sufficiently informed by their physician about various aspects of Duchenne muscular dystrophy. The group of patients reporting insufficient information about breathing problems was composed of $47.1 \%$ ambulatory and $61.0 \%$ non-ambulatory patients.

\section{Overall satisfaction with treatment}

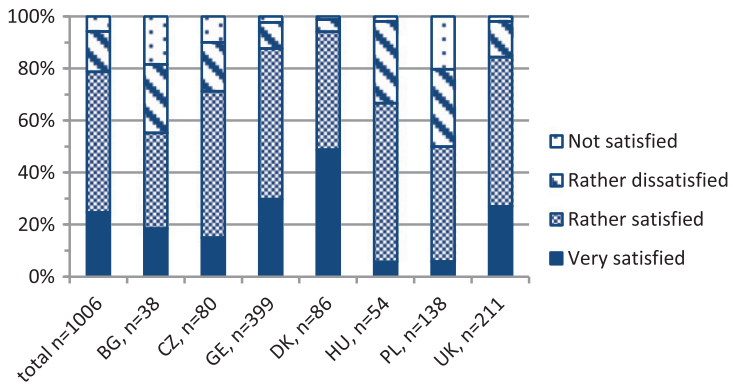

Fig. 3. shows the percentages of patients with Duchenne muscular dystrophy of each country reporting the degree of overall satisfaction with the medical treatment on a four-point scale (very satisfied, rather satisfied, rather dissatisfied, not satisfied). The absolute number of evaluated questionnaires (n) is indicated for the whole cohort and for each country at the $\mathrm{X}$-axis. $\mathrm{BG}=$ Bulgaria, $\mathrm{CZ}=$ Czech Republic, $\mathrm{GE}=$ Germany, $\mathrm{DK}=$ Denmark, $\mathrm{HU}=$ Hungary, $\mathrm{PL}=$ Poland, $\mathrm{UK}=$ United Kingdom.

Our data reflect patient and family perspectives on DMD care, and indicate a large proportion of patients (i) feel insufficiently informed about all care aspects in the survey and (ii) are unaware of critical aspects of their individual health, namely pulmonary or cardiac function. Whether the information deficit reflects insufficient provision or poor retention of information is unclear. Regardless, our data identify an education deficit that if rectified, could improve patient empowerment for appropriate monitoring and care. We did not request names of care-giving centres/hospitals to preserve patient anonymity, and thus quality of 
care in specific facilities cannot be determined from our data. Our patient-centred survey approach put restrictions on detail, since time required to complete the survey was limited to achieve maximal evaluable responses. We balanced covering a wide range of disease aspects with enough detail to sufficiently analyse data. Therefore, this survey did not cover all aspects of DMD care addressed in care standards. The high response rate $(63 \%)$ exceeded our expectations compared to other surveys, and reflects the strong interest of patients/families in assisting to improve DMD care.

Early DMD diagnosis is necessary for early initiation of preventive measures. Moreover, new genespecific approaches are more likely to be successful if applied at an early stage of the condition. Patients were $\sim 4$ years old at diagnosis in most European countries. This is younger than previously reported in the UK and United States [8, 9]. Our analysis reveals that DMD patients are being diagnosed younger, likely reflecting improved access to diagnostics and increased primary physician awareness. Affected families benefit from reduced time to diagnosis, since they spend less time with uncertainty and have more time to consider family planning. Our survey confirms genetic testing in nearly all newly diagnosed patients, but reveals genetic testing still does not reach all older European DMD patients.

Sufficient information about typical disease course is crucial for care-providers, patients, and families, since this influences medical care and personal planning for future education and living. We gathered broad information describing patients' current neuromuscular situations and disease course as well as treatment and informedness level. Patients who receive(d) corticosteroids lost ambulation later than untreated patients, albeit the ambulatory time gained was less than in other studies with probably more uniform patient cohorts [10]. Overall mean ambulatory loss, regardless of corticosteroid use, was also earlier $(10.4 y)$ than expected $[11,12]$. Although our study was not designed to analyse corticosteroid influence on ambulation, it portrays real-life corticosteroid use in European patients, and despite patient heterogeneity, supports the well-known beneficial effect of corticosteroids on ambulation. Our results concur with a another large observational study of steroid-use in real-life practice in Japan [13]. Our data reveal marked differences between countries, with the lowest corticosteroid use in Bulgaria, the Czech Republic, and Denmark. Economic reasons, insufficient information, or as yet unidentified cultural or country-specific issues may discourage corticosteroid use. We recommend efforts be increased to educate patients/parents in detail about corticosteroid benefits and side-effect management to minimize fear. The large majority of our cohort who were regularly treated in centres had at least tried corticosteroids, in contrast to those treated elsewhere.

Care standards recommend physiotherapeutic preventive measures begin in the presymptomatic stage and continue throughout life to minimize contractures in upper and lower extremities, preserve function and reduce pain. Our data show that just under a quarter of children and one third of adults did not receive any physiotherapy. Lack of professional physiotherapy may partially be compensated by sufficient instruction for in-home exercises. Our results convey an urgent need to improve information transfer to patients/families about the importance of regular stretching to improve success of professional physiotherapy and training programmes for in-home stretching exercises. Almost half of respondents were non-ambulatory, emphasising the need for comprehensive optimised care focussing on maintaining upper extremity motor function and managing scoliosis. Preserving hand function is essential for patients to independently use a wheelchair, other assistive devices, or computers, and to eat or take part in education or a profession [14]. The mean age at which hand function was lost was 26 years, but our oldest patient still capable of using hands to move an electric wheelchair was 41.9 years old. Our survey and other reports [15] suggest upper limb function varies greatly and give proof-of-principle for maintaining meaningful hand function into the fourth decade. The current life expectancy of $\geq 30$ years $[16,17]$ and a mean "late-ambulatory II" age of 19 years from our data indicate patients spend $>10$ years with impaired hand function, emphasising the importance of preventive and therapeutic measures to maintain hand function $[14,18]$. Sitting ability facilitates mobility, social participation, eating, and eye-level communication, but becomes impaired by scoliosis, a frequent complication in non-ambulatory DMD patients [19, 20]. Standards recommend regular monitoring and surgical correction for scoliosis in non-ambulatory patients [4]. Efforts should be made to more consistently realise this recommendation, since nearly $30 \%$ of our surveyed non-ambulatory participants reported never receiving spinal radiography or inspection.

Regular care from neuromuscular specialists is recommended [4], and our survey supports that specialised neuromuscular centres provide best-practice 
Table 4

Results of process indicators for cardiac and pulmonary care in DMD patient subgroups

\begin{tabular}{|c|c|c|c|}
\hline Characteristic $^{\mathrm{a}}$ & $\begin{array}{l}\text { Check-ups according to } \\
\text { recommendation }\end{array}$ & Less frequent check-ups & No check-ups \\
\hline $\begin{array}{l}\text { Lung function testing in ambulatory } \\
\text { patients } \geq 6 \text { years }(n=331 / 348)\end{array}$ & $63.7 \%$ & $12.9 \%$ & $23.3 \%$ \\
\hline $\begin{array}{l}\text { Lung function testing in non-ambulatory } \\
\text { patients } \geq 6 \text { years }(n=546 / 567)\end{array}$ & $30.6 \%$ & $59.3 \%$ & $10.1 \%$ \\
\hline $\begin{array}{l}\text { Echocardiography in patients } \geq 10 \text { years } \\
(n=635 / 660)\end{array}$ & $77.9 \%$ & $17.7 \%$ & $4.4 \%$ \\
\hline
\end{tabular}

Table 5

Results of selected outcome and care indicators for DMD patients regularly and irregularly seeking care at a neuromuscular centre

\begin{tabular}{|c|c|c|c|}
\hline Characteristic & $\begin{array}{l}\text { Regular visitors }^{\mathrm{a}} \\
\quad(n=841)\end{array}$ & $\begin{array}{l}\text { Irregular visitors }^{\mathrm{b}} \\
\quad(n=186)\end{array}$ & Difference \\
\hline Mean patient age in years \pm SD & $12.1 \pm 6.3$ & $17.3 \pm 9.3$ & $p<0.0001^{\mathrm{c}}$ \\
\hline No regular ${ }^{\mathrm{d}}$ cardiac check ups & $21.0 \%$ & $52.3 \%$ & $p<0.001^{\mathrm{e}}$ \\
\hline No regular ${ }^{\mathrm{d}}$ pulmonary check-ups & $30.9 \%$ & $71.1 \%$ & $p<0.001^{\mathrm{e}}$ \\
\hline Satisfaction with treatment & $83 \%$ & $50 \%$ & $p<0.001^{\mathrm{e}}$ \\
\hline $\begin{array}{l}\text { Patients } \geq 9 \text { years of age reporting current } \\
\text { or past corticosteroid use }\end{array}$ & $73.0 \%$ & $37.2 \%$ & $p<0.001^{\mathrm{e}}$ \\
\hline $\begin{array}{l}\text { Patients who reported unplanned } \\
\text { admissions to hospital }\end{array}$ & $13.8 \%$ & $15 \%$ & n.s. \\
\hline $\begin{array}{l}\text { Mean duration of hospital stay } \\
\text { for the unplanned admissions }\end{array}$ & $9.3 \pm 3.7$ & $23.0 \pm 11.8$ & $p<0.05^{\mathrm{e}}$ \\
\hline
\end{tabular}

$\mathrm{SD}=$ standard deviation. ${ }^{\mathrm{a}}$ Defined as visiting a neuromuscular centre at least once yearly. ${ }^{\mathrm{b}}$ Including patients who sought care less than once yearly $(n=78)$ or never $(n=109) .{ }^{\mathrm{c}}$ Student's $t$-test. ${ }^{\mathrm{d}}$ Defined as at least yearly. ${ }^{\mathrm{e}}$ Wilcoxon test.

care for DMD patients. Process indicators, including sufficient information about disease aspects, regular assessments, and corticosteroid treatment, as well as outcome indicators, including overall satisfaction with medical care and unplanned hospital stay duration, indicated patients regularly visiting neuromuscular centres were better situated. This is in line with findings in patients with cystic fibrosis or other life-limiting chronic conditions [21, 22]. Our survey shows that $10 \%$ of patients ( $25 \%$ of adults) never received care from a neuromuscular specialist. Therefore, DMD care may be improved by better information and better access to neuromuscular centres. We confirmed that care from a neuromuscular specialist could reduce duration of stay during unplanned hospital admissions.

Cardiomyopathy is a major source of morbidity and mortality in DMD patients, especially in the second decade [23]. Observational studies have shown that $\beta$-blockers [24] can delay progression of left ventricular dysfunction. Our survey reveals that nearly one third of patients meeting the criteria for cardiomyopathy reported not receiving medical treat- ment. An important first step to improve cardiac care would be improving patient education, with the goal of making the DMD patient an expert to increase patient investment, especially at the transition from paediatric to adult cardiac care [25].

Appropriate pulmonary care, including secretion management and non-invasive ventilation, has probably the largest impact on quality of life and survival in adolescent and adult DMD patients [16]. One quarter of patients reporting a FVC $<20 \%$ were without mechanical ventilation, and the percentage is likely to be even higher in patients who were not tested or did not know their pulmonary function values. Although many unplanned hospital admissions were attributed to acute respiratory problems, we detected no correlation between regular pulmonary function assessment and unplanned hospitalisation.

Once considered a childhood disease, DMD must now be redefined as a disease beginning in childhood but continuing into adult life, making the transition from paediatric to adult-oriented healthcare ever more important [26]. The lack of nearby neuromuscular centres for adult patients and reduced mobility 
in advanced disease stages contributed to the large number of adults not receiving care from neuromuscular specialists. Our results emphasise the need for a coordinated transition from child- to adult-centred care and comprehensive, multidisciplinary care and social support for the growing number of adults living with DMD [27].

Our cross sectional survey of $>1,000$ European DMD patients shows that despite development and broad dissemination of multidisciplinary care guidelines many patients still do not receive recommended interventions and treatments likely to improve quality of life. The neglected population is probably underestimated by our survey, due to the unavoidable bias associated with recruiting patients via patient registries. Assuring the implementation of recommended care standards remains the best way to ensure the highest quality of life for DMD patients, and still has room for improvement in Europe.

\section{ACKNOWLEDGMENTS}

The authors warmly thank both patients and families who participated. We gratefully acknowledge project financing from the EU Executive Agency for Health and Consumers (\#20091205), all members of the CARE-NMD team and all CARE-NMD collaborating partners, a full list of whom is available on the project website, the TREAT-NMD network (EU 6th Framework Programme \#LSHM-CT-2006-036825) and national DMD registries for their logistical support in performing the survey, and Kathy Astrahantseff for editing the paper. Further support came from the EU 7th Framework Programme for the RD-Connect (\#305444, to HL, KB) and Neuromics (\#305121, to HL, KB, JK) projects.

\section{ETHICAL STANDARDS}

This study has been approved by the appropriate ethics committee and all persons gave their informed consent prior to their inclusion in the study.

\section{INTERPRETATION}

Our survey provides a detailed picture of the current DMD patient population in Europe and their care situation. Disparities between the adult and the paediatric patient population were more pronounced than between different countries.

\section{FUNDING}

The EU Executive Agency for Health and Consumers funded the CARE-NMD project (\#20091205).

\section{CONFLICT OF INTEREST}

This study was supported by the EU Executive Agency for Health and Consumers as CARE-NMD project (\#20091205).

\section{SUPPLEMENTARY MATERIAL}

The supplementary material is available in the electronic version of this article: http://dx.doi.org/ $10.3233 / J N D-160185$.

\section{REFERENCES}

[1] Mendell JR, Shilling C, Leslie ND, Flanigan KM, al-Dahhak $\mathrm{R}$, Gastier-Foster J, et al. Evidence-based path to newborn screening for Duchenne muscular dystrophy. Ann Neurol. 2012;71(3):304-13.

[2] Brooke MH, Fenichel GM, Griggs RC. Duchenne Dystrophy: Patterns of clinical progression and effects of supportive therapy. Neurology. 1989;39:475-81.

[3] Bushby K, Finkel R, Birnkrant DJ, Case LE, Clemens PR, Cripe L, et al. Diagnosis and management of Duchenne muscular dystrophy, part 1: Diagnosis, and pharmacological and psychosocial management. Lancet Neurol. 2010;9(1): 77-93.

[4] Bushby K, Finkel R, Birnkrant DJ, Case LE, Clemens PR, Cripe L, et al. Diagnosis and management of Duchenne muscular dystrophy, part 2: Implementation of multidisciplinary care. Lancet Neurol. 2010;9(2):177-89.

[5] Bladen CL, Rafferty K, Straub V, Monges S, Moresco A, Dawkins H, et al. The TREAT-NMD Duchenne muscular dystrophy registries: Conception, design, and utilization by industry and academia. Hum Mutat. 2013;34(11): 1449-57.

[6] Steffensen B, Hyde S, Lyager S, Mattsson E. Validity of the EK scale: A functional assessment of non-ambulatory individuals with Duchenne muscular dystrophy or spinal muscular atrophy. Physiother Res Int. 2001;6(3):119-34.

[7] Ward S, Chatwin M, Heather S, Simonds AK. Randomised controlled trial of non-invasive ventilation (NIV) for nocturnal hypoventilation in neuromuscular and chest wall disease patients with daytime normocapnia. Thorax. 2005;60(12):1019-24.

[8] Bushby KM, Hill A, Steele JG. Failure of early diagnosis in symptomatic Duchenne muscular dystrophy. Lancet. 1999;353(9152):557-8.

[9] Ciafaloni E, Fox DJ, Pandya S, Westfield CP, Puzhankara S, Romitti PA, et al. Delayed diagnosis in duchenne muscular dystrophy: Data from the Muscular Dystrophy Surveillance, Tracking, and Research Network (MD STARnet). J Pediatr. 2009;155(3):380-5.

[10] Ricotti V, Ridout DA, Scott E, Quinlivan R, Robb SA, Manzur AY, et al. Long-term benefits and adverse effects 
of intermittent versus daily glucocorticoids in boys with Duchenne muscular dystrophy. J Neurol Neurosurg Psychiatry. 2013;84(6):698-705.

[11] Mirski KT, Crawford TO. Motor and Cognitive Delay in Duchenne Muscular Dystrophy: Implication for Early Diagnosis. J Pediatr. 2014;165(5):1008-10.

[12] Goemans N, Buyse G. Current treatment and management of dystrophinopathies. Curr Treat Options Neurol. 2014;16(5):287.

[13] Takeuchi F, Yonemoto N, Nakamura H, Shimizu R, Komaki $\mathrm{H}$, Mori-Yoshimura M, et al. Prednisolone improves walking in Japanese Duchenne muscular dystrophy patients. J Neurol. 2013;260(12):3023-9.

[14] Janssen MM, Bergsma A, Geurts AC, De Groot IJ. Patterns of decline in upper limb function of boys and men with DMD: An international survey. J Neurol. 2014;261(7): 1269-88.

[15] Bartels B, Pangalila RF, Bergen MP, Cobben NA, Stam HJ, Roebroeck ME. Upper limb function in adults with Duchenne muscular dystrophy. J Rehabil Med. 2011;43(9): 770-5.

[16] Eagle M, Bourke J, Bullock R, Gibson M, Mehta J, Giddings D, et al. Managing Duchenne muscular dystrophy-the additive effect of spinal surgery and home nocturnal ventilation in improving survival. Neuromuscul Disord. 2007;17(6):470-5.

[17] Kohler M, Clarenbach CF, Bahler C, Brack T, Russi EW, Bloch KE. Disability and survival in Duchenne muscular dystrophy. J Neurol Neurosurg Psychiatry. 2009;80(3): 320-5.

[18] Alemdaroglu I, Karaduman A, Yilmaz OT, Topaloglu H. Different types of upper extremity exercise training in Duchenne muscular dystrophy: Effects on functional performance, strength, endurance, and ambulation. Muscle Nerve. 2014;51(5):697-705.

[19] Shapiro F, Zurakowski D, Bui T, Darras BT. Progression of spinal deformity in wheelchair-dependent patients with Duchenne muscular dystrophy who are not treated with steroids: Coronal plane (scoliosis) and sagittal plane (kyphosis, lordosis) deformity. Bone Joint J. 2014;96$\mathrm{B}(1): 100-5$.

[20] Hsu JD, Quinlivan R. Scoliosis in Duchenne muscular dystrophy (DMD). Neuromuscul Disord. 2013;23(8):611-7.

[21] Lannon CM, Peterson LE. Pediatric collaborative networks for quality improvement and research. Acad Pediatr. 2013;13(6 Suppl):S69-S74.

[22] Anderson JB, Beekman RH, III, Kugler JD, Rosenthal GL, Jenkins KJ, Klitzner TS, et al. Use of a Learning Network to Improve Variation in Interstage Weight Gain after the Norwood Operation. Congenit Heart Dis. 2014;9(6): 512-20.

[23] Spurney C, Shimizu R, Morgenroth LP, Kolski H, GordishDressman H, Clemens PR. Cooperative International Neuromuscular Research Group Duchenne Natural History Study demonstrates insufficient diagnosis and treatment of cardiomyopathy in Duchenne muscular dystrophy. Muscle Nerve. 2014;50(2):250-6.

[24] Jefferies JL, Eidem BW, Belmont JW, Craigen WJ, Ware SM, Fernbach SD, et al. Genetic predictors and remodeling of dilated cardiomyopathy in muscular dystrophy. Circulation. 2005;112(18):2799-804.

[25] Abbott D, Carpenter J. Wasting precious time: Young men with Duchenne muscular dystrophy negotiate the transition to adulthood. Disability \& Society. 2014;29(8):1192-205.

[26] Schrans DG, Abbott D, Peay HL, Pangalila RF, Vroom E, Goemans N, et al. Transition in Duchenne muscular dystrophy: An expert meeting report and description of transition needs in an emergent patient population: (Parent Project Muscular Dystrophy Transition Expert Meeting 17-18 June 2011, Amsterdam, The Netherlands). Neuromuscul Disord. 2013;23(3):283-6.

[27] Rodger S, Woods KL, Bladen CL, Stringer A, Vry J, Gramsch K, et al. Adult care for Duchenne muscular dystrophy in the UK. J Neurol. 2015;262(3):629-41. 